\title{
Radiological and functional outcome of displaced mid-shaft clavicular fracture managed with open reduction and internal fixation with precountered anatomical clavicular locking plate: a prospective study
}

\author{
Sagar Panthi*, Rishiswor Shrestha, Rajan Shakya
}

Department of Orthopaedics and Traumatology, Rapti Academy of Health Science, Ghorahi, Dang, Nepal

Received: 26 May 2020

Revised: 04 July 2020

Accepted: 10 July 2020

\author{
*Correspondence: \\ Dr. Sagar Panthi, \\ E-mail: drsagarmsortho@gmail.com
}

Copyright: () the author(s), publisher and licensee Medip Academy. This is an open-access article distributed under the terms of the Creative Commons Attribution Non-Commercial License, which permits unrestricted non-commercial use, distribution, and reproduction in any medium, provided the original work is properly cited.

\begin{abstract}
Background: Displaced mid-shaft clavicular fractures are treated by conservative methods which shows higher rate of malunion and non-union with suboptimal outcomes. Fracture fixation by pre-countered anatomical clavicular locking plate avoids these complications. This study aims to assess the radiological and functional outcome after open reduction and internal fixation by pre-countered anatomical clavicular locking plate.

Methods: Fifty patients of mid-shaft clavicular fractures with age group of 18 to 60 years were treated with open reduction and internal fixation with precountered anatomical clavicular locking plate from, in the span of November 2018 to May 2020. All the patients were followed up for six months for the study. Final functional outcome was assessed in six months.

Results: All the fractures united at the average time of $16.32 \pm 2.37$ weeks. Mean Constant and Murley score was 96.0 \pm 5.20 . The outcome was graded as excellent in $45(90 \%)$, good in $4(8 \%)$ and fair in $1(2 \%)$ patients.

Conclusions: Hence displaced mid-shaft clavicular fractures can be treated with by precountered anatomical clavicular locking plate.
\end{abstract}

Keywords: Anatomical plate, Mid-shaft clavicular fracture, Open reduction, Internal fixation

\section{INTRODUCTION}

Fracture of clavicle is a common traumatic injury around shoulder due to its subcutaneous position and it accounts for approximately $2.6 \%$ to $12 \%$ of all fractures and $44 \%$ to $66 \%$ of fractures about the shoulder region. Middle third fractures account for $80 \%$ of all clavicle fractures this is because the junction between the two crosssectional configurations occurs in the middle third and is a vulnerable area to break for fracture, especially with axial loading. Moreover, the middle third lacks reinforcement by muscles or ligaments distal to the subclavius insertion, resulting in additional vulnerability. ${ }^{1,2}$

There are many methods described to treat clavicle fractures. ${ }^{3}$ Roughly these methods can be divided into conservative and surgical methods. Conservative methods consist of applying a simple sling, clavicular brace or figure of eight bandage. Conservative management has the advantages of being cheap, affordable and is devoid of the risks of anesthesia. But there are certain disadvantages that conservative methods are associated with risk of non-union, residual deformity and patient dissatisfaction. ${ }^{4,5}$ Recent studies shows non-union rates 
up to $15 \%$ and patient dissatisfaction of up to $31 \%$ following conservative management. ${ }^{6}$ Treating those with shortening of more than two $\mathrm{cm}$ by simple splintage is now believed to produce a considerable risk of symptomatic mal-union mainly pain and lack of power during shoulder movements and an increased incidence of non-union therefore operative methods have evolved as a better option and there is improved patient-oriented outcomes compared to that of operative treatment that is considering incidence of nonunion, functional outcome, pain scores, quality of life, cosmetic aspect and complication. The goals of treatment of mid-shaft clavicle fracture are to restore normal anatomy, limit pain and promote quick return to activity or play. ${ }^{7,8}$

The surgical indication for mid-shaft clavicle fractures is controversial and has been changing recently. The accepted indications for operative treatment of clavicular fracture are open fracture, associated neurovascular compromise and skin tenting with potential for progression to open fracture along with substantial displacement, comminution ( $\mathrm{Z}$ deformity) and shortening greater than one to two $\mathrm{cm}^{9}$

There are various operative methods for treatment of mid-shaft clavicle fracture which includes intramedullary devices, plates, and external fixators.

Plating of mid-shaft clavicle fracture is preferred method of fixation by many authors. Biomechanically, plate fixation is superior to intramedullary fixation because it better resists the bending and torsional forces that occur during elevation of the upper extremity above shoulder level. Patient can be allowed full range of motion once their soft tissue have healed. Disadvantages of plate fixation include the necessity for increased exposure and soft tissue stripping, potential injury to the supraclavicular nerves, higher infection rates and the refracture after plate removal these complications can be reduced by careful soft tissue handling, minimal periosteal stripping and meticulous plate fixation. ${ }^{3}$

In our study we used the locking plate which provide stiffer constructs and are useful in patients with osteoporotic bone and severely comminuted fractures and also this plate also provides rigid fixation, rotational control over the fracture, and ability for cortical compression at the site. The surgeon also doesn't need to contour the plate which retrains mechanical strength and has less soft tissue related problems. This plate has less hardware prominence and there is no need of implant removal after fracture healing as compared to traditional plate. ${ }^{10-12}$

The aim of this prospective study was to assess the radiological and functional outcome of mid-shaft clavicular fracture treated by open reduction and internal fixation with precountered anatomical locking plate.

\section{METHODS}

A prospective study was conducted in Rapti Academy of Health Science, Ghorahi, Dang from the period extending from November 2018 to May 2020. Fifty patients with displaced mid-shaft clavicular fracture treated with open reduction and internal fixation with precountered anatomical clavicular locking plate. Permission from Institutional review committee (Ethical board) was obtained. Cases presenting to Emergency and outpatient department fulfilling the inclusion criteria were selected for the study (Table 1). Exclusion criteria were also described for careful selection of the cases.

Table 1: Inclusion and exclusion criteria

\begin{tabular}{|ll|}
\hline Criteria & Description \\
& $\begin{array}{l}\text { Adult patient above } 18 \text { years and below } \\
60 \text { years who require surgical intervention } \\
\text { for displacement and comminution at } \\
\text { middle third clavicle fracture. }\end{array}$ \\
\cline { 2 - 2 } & $\begin{array}{l}\text { Skin tenting with the potential of fracture } \\
\text { to open fracture. }\end{array}$ \\
& Age less than 18 years. \\
\hline \multirow{5}{*}{ Exclusion } & $\begin{array}{l}\text { Fracture in medial or lateral third of } \\
\text { clavicle, pathological fracture, } \\
\text { undisplaced fracture, open fracture and } \\
\text { fracture associated with neurovascular } \\
\text { injury. }\end{array}$ \\
\cline { 2 - 2 } & $\begin{array}{l}\text { Established non-union from previous } \\
\text { fracture }\end{array}$ \\
& Any medical contraindication to surgery \\
\hline & $\begin{array}{l}\text { Patients not giving informed consent for } \\
\text { surgery }\end{array}$ \\
\hline
\end{tabular}

Informed consent was obtained from all the patients included in the study. Fracture displacement was characterized as fracture shortening greater than $2 \mathrm{~cm} .{ }^{13}$

All patients of shoulder injuries with suspected displaced clavicle fractures were hospitalized and subjected to detailed general and clinical examination. The patient was given first aid with sling.

The diagnosis and displacement of clavicle fracture was confirmed by X-rays. Standard Anteroposterior (AP) radiographs of affected shoulder were generally sufficient to confirm the presence of clavicle fracture and degree of fracture displacement. On the basis of X-ray, the site of fracture, pattern of fracture and degree of displacement were ascertained and the fracture were classified according to Robinson classification which were considered in this study and were planned for surgery.

All surgeries were performed under interscalene block with anterior cervical plexus block. All patients were put in beach chair position with a bolster in interscapular space turning the head on opposite side and upper extremity in the involved side was disinfected and 
drapped free for mobilization. Preoperatively, $1 \mathrm{~g}$ of intravenous ceftriaxone was administered. An oblique incision was made cantered superiorly over the fracture site. The subcutaneous tissue and platysma muscle were kept together as one layer and extensively mobilized, especially proximally and distally. Care was taken to identify, isolate and protect any visible, larger branches of the supraclavicular nerves. The fracture site was identified and the fracture was reduced and fixed with precountered anatomical clavicular locking plate on superior or anterosuperior surface of bone according to fracture and bony configuration with at least 6 cortical purchases on either side. Cancellous screws were used as necessary at the lateral end for better purchase in cancellous bone. Interfragmentary screw was placed according to requirement. Incision was closed in two layers. The limb was supported with arm pouch sling post operatively.

Wound was inspected on second day and patient was discharged on third or fifth postoperative day if the wound was satisfactory. A sling was used for comfort for seven to ten days and then a physiotherapist instructed the patient in active range of motion exercise that was performed at home. On two weeks follow-up, the suture was removed and check X-ray was done. Next follow up was done in six weeks, where repeat of X-ray was done. Subsequent follow-up was done in three months and six months. At six months follow-up, final outcome was evaluated using Constant and Murley Score. ${ }^{14}$

All data were entered and analyzed using SPSS 21. Mean and SD was used for descriptive analysis.

\section{RESULTS}

There were 50 patients. Majority of the patients, 32 $(64 \%)$ were male and $18(36 \%)$ were female. The mean age of patient was 35.1 years (range 18 to 59) years. 30 (60\%) patients had right clavicle fractures and $20(40 \%)$ had left clavicle fracture.

The most common mechanism of injury was motor vehicle accident in $25(50 \%)$, fall in $21(42 \%)$ and sports injury in $4(8 \%)$. 6 patients $(12 \%)$ had associated injuries. 2 patients had associated ribs fracture which was managed conservatively. One patient had Shaft of femur fracture which was managed with closed intramedullary interlocking nail in same setting. One patient had closed tibia and fibula fracture which was managed with closed intramedullary interlocking nail in same setting. 1 patient had distal radius fracture managed with open reduction and internal fixation with volar locking plate in same setting and 1 patient had compound distal tibia and fibula fracture which was managed with Spanning External fixator in same setting.

The most common fracture according to Robinson classification were type 2B1 (52\%), type 2B2 (26\%) and type 2A2 $(22 \%)$. Mean time of fracture union in all patients was 16.32 type of fractures 2.37 at final followup. The mean union time of Robinson type $2 \mathrm{~A} 2$ was $15.45 \pm 2.50$ weeks, type $2 \mathrm{~B} 1$ was $15.2 \pm 1.66$ weeks and type $2 \mathrm{~B} 2$ was $19.15 \pm 0.55$ weeks (Table 2 ).

Table 2: Distribution of patients showing union time in relation to pattern of fracture according to Robinson classification.

\begin{tabular}{|c|c|c|c|c|c|c|}
\hline \multirow{3}{*}{ Union in weeks } & \multicolumn{6}{|c|}{ Type of fractures } \\
\hline & \multicolumn{2}{|c|}{$2 \mathrm{~A} 2$} & \multicolumn{2}{|c|}{ 2B1 } & \multicolumn{2}{|c|}{ 2B2 } \\
\hline & $\mathbf{N}$ & $\%$ & $\mathbf{N}$ & $\%$ & $\mathbf{N}$ & $\%$ \\
\hline $10-12$ & 2 & 4 & 2 & 4 & 0 & 0 \\
\hline 13-15 & 3 & 6 & 11 & 22 & 0 & 0 \\
\hline $16-18$ & 6 & 12 & 12 & 24 & 1 & 2 \\
\hline 19-21 & 0 & 0 & 1 & 2 & 12 & 24 \\
\hline Average union \pm SD & \multicolumn{2}{|c|}{$15.45 \pm 2.50$} & \multicolumn{2}{|c|}{$15.27 \pm 1.66$} & \multicolumn{2}{|c|}{$19.15 \pm 0.55$} \\
\hline
\end{tabular}

Table 3: Distribution of patients showing relationship between evidence of union to age of patient.

\begin{tabular}{|c|c|c|c|c|c|}
\hline \multirow{2}{*}{ Evidence of union in weeks } & \multicolumn{5}{|c|}{ Age of patients in years } \\
\hline & $10-20$ & 21-30 & 31-40 & 41-50 & $51-60$ \\
\hline 10-12 & 4 & 0 & 0 & 0 & 0 \\
\hline 13-15 & 0 & 11 & 0 & 2 & 1 \\
\hline 16-18 & 0 & 3 & 3 & 9 & 4 \\
\hline $19-21$ & 1 & 7 & 3 & 0 & 2 \\
\hline Average union in weeks \pm SD & $13.40 \pm 3.13$ & $16.29 \pm 2.43$ & $17.83 \pm 1.47$ & $16.36 \pm 1.28$ & $17.14 \pm 2.26$ \\
\hline
\end{tabular}


Fracture in age group of 10-20 years united at an average of 13.40 \pm 3.13 weeks, 21-30 years at an average of $16.29 \pm 2.43$ weeks, $31-40$ years at an average of $17.83 \pm 1.47$ weeks and 51-60 years at an average of $17.14 \pm 2.26$ weeks (Table 3 ).

The outcome was graded as excellent in $45(90 \%)$ patients, good in $4(8 \%)$ patients and fair in $1(2 \%)$ patients. Mean Constant and Murley score at final followup was 96.0 \pm 5.20 (Table 4).

Table 4: Functional outcome at final follow-up by Constant and Murley score $(n=50)$.

\begin{tabular}{|lll|}
\hline Outcome & No. of patients & Percentage (\%) \\
\hline Excellent & 45 & 90 \\
\hline Good & 4 & 8 \\
\hline Fair & 1 & 2 \\
\hline Poor & 0 & 0 \\
\hline Total & 50 & 100 \\
\hline
\end{tabular}

One patient developed superficial wound infection which resolved with administration of intravenous antibiotics for few days. None of the patient developed non-union, implant failure, plate exposure, deep infection and screw loosening in our study.

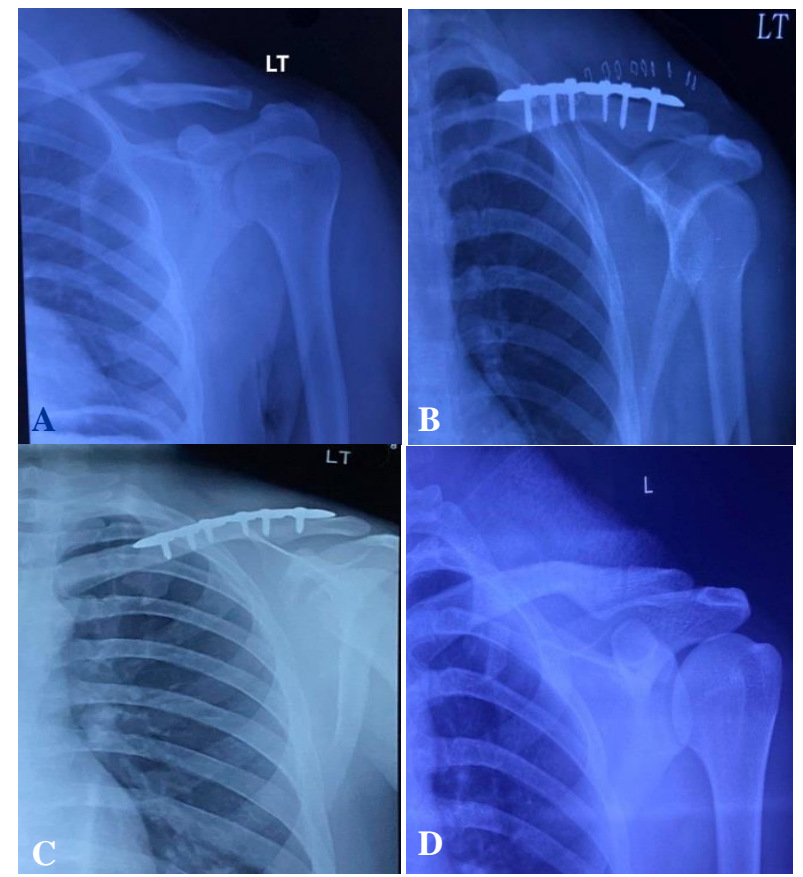

Figure 1: Radiographs anteroposterior view showing fracture of mid-shaft clavicle. (A) Pre-operative, (B)

Post-operative, (C) 6 months follow up, (D) After implant removal.

\section{DISCUSSION}

Traditionally clavicle fracture have been treated by different conservative methods like arm sling, figure of eight bandage. None of the method reduces the fracture but arm sling results better patient satisfaction with lesser side effects. ${ }^{15}$ Many earlier studies like in 1960's, Neer and Rowe where Neer reported non-union in only three patients among 2235 with middle third fracture treated by closed methods while Rowe reported non-union in four of 566 clavicular fractures. ${ }^{16,17}$

Hill et al. reported that eight patients had a non-union and 16 patients had an unsatisfactory outcome. ${ }^{6}$ Robinson et al. described a consecutive series of 868 patients with clavicular fracture, 581 of whom had a mid-shaft diaphyseal fracture where significant higher non-union rate $21 \%$ for displaced, comminuted mid-shaft fractures $(\mathrm{p}<0.005){ }^{7}$ Brinker et al analyzed the data in that study and suggested nonunion rate of ranging between $20 \%$ and $33 \%$ for displaced comminuted fracture. ${ }^{18}$ In the metaanalysis of the literature 1975 to 2005 by Zlowodzky et al. found non-union rate to be exponentially higher which were treated non-operatively. ${ }^{3}$

In our study $50 \%$ of cases developed clavicle fracture following motor vehicle accidents followed by fall in $42 \%$ of cases and sports Injury in $8 \%$. Similar study done by McKee et al and Zlowodzky et al described a motor vehicle accident is the most common mode of injury. ${ }^{19,3}$ There is slightly higher incidence of motor vehicle accident as a major cause of clavicle fracture might be because of the fact this hospital is located in the region which is prone for motor vehicle accidents.

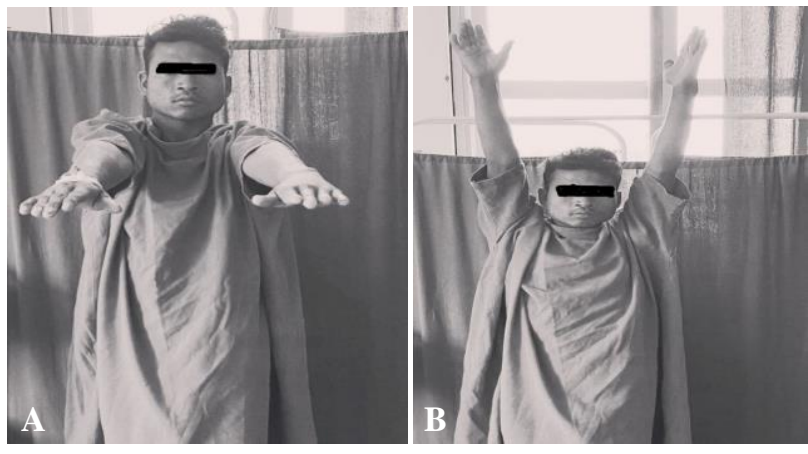

Figure 2: Clinical picture at final follow up. (A) Good forward flexion, (B) normal overhead abduction.

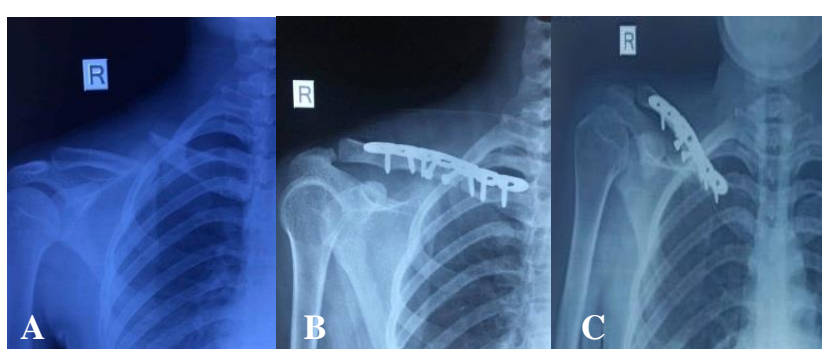

Figure 3: Follow up of clavicular fracture fixation. (A) Pre-operative, (B) post-operative, (C) after 6 months.

All patients with mid-shaft clavicle fracture were of closed type. This is comparable to study done by 
Bostman et al and Cho et al which also showed all their patients were closed fractures. ${ }^{20,21}$

According to Robinson classification, 2A2 Type was seen in $22 \%, 2 \mathrm{~B} 1$ was seen in $52 \%, 2 \mathrm{~B} 2$ was seen in $26 \%$ of the patients suggesting Robinson Type 2B1 (Displaced with simple or butterfly fragment) were more common which is similar to the study done by Bostman et al that includes Robinson type 2B1 was common in 81 patients $(78.64 \%)$ and only 22 patients $(23.36 \%)$ were of Robinson type $2 \mathrm{~B} 2 .^{20}$

Mckee et al described the average duration of fracture union were 14 to 16 weeks in those patient who underwent surgery and 24 to 28 weeks in those patients who were managed conservatively in mid-shaft clavicular fractures. ${ }^{19}$ The average time of fracture union was $16.32 \pm 2.37$ weeks. Fracture in age group 10 to 20 years patients united at an average of $13.40 \pm 3.13$ weeks, 21 to 30 years age group united at an average of $16.29 \pm 2.43$ weeks, 31-40 years age group united at an average of $17.83 \pm 1.47$ weeks, 41 to 50 years age group united at an average of $16.36 \pm 1.28$ weeks while 51 to 60 years age group united at an average of $17.14 \pm 2.26$ weeks. As per Constant and Murley score 45 (90\%) of the study subjects showed excellent results, $4(8 \%)$ showed good results, $1(2 \%)$ showed good results. Mean Constant and Murley score was $96.0 \pm 5.20$ which is similar to study done by Dhoju D et al with average fracture union was 16 weeks with mean Constant and Murley score of 97.45 at one year follow-up in 20 patients. ${ }^{22}$

In the study done by Wang et al revealed that primary operative fixation could effectively reduce the rates of nonunion, symptomatic mal-union, neurological symptoms and overall complications. In addition, Constant scores were significantly improved after operative fixation compared with non-operative treatment after a follow up of one year or more. Based on current clinical reports, study concluded that operative treatment is superior to non-operative treatment in the management of displaced mid-shaft clavicle fractures. ${ }^{23}$

\section{CONCLUSION}

Management of Displaced Mid-shaft clavicle fracture in adults, with locking plate seems to be safe and stable method. This modality of treatment provides more rigid fixation with locking plate and screws for fresh displaced or comminuted mid-shaft clavicle fracture which gives good anatomical reduction, immediate pain relief and does not require immobilization for longer periods preventing the development of shoulder stiffness.

Funding: No funding sources Conflict of interest: None declared

Ethical approval: The study was approved by the institutional ethics committee

\section{REFERENCES}

1. Lenza M, Faloppa F. Surgical interventions for treating acute fractures or non-union of the middle third of the clavicle. Cochrane Database Syst Rev. 2015;7(5):CD007428.

2. Nowak J, Mallmin H, Larsson S. The aetiology and epidemiology of clavicular fractures. A prospective study during a two-year period in Uppsala, Sweden. Injury. 2000;31(5):353-8.

3. Zlowodzki M, Zelle BA, Cole PA, Jeray K, Mckee MD. Treatment of acute midshaft clavicle fractures: systematic review of 2144 fractures: on behalf of the evidence-based orthopaedic trauma working group. J Orthop Trauma. 2005;19(7):504-7.

4. Lester CW. The treatment of fractures of the clavicle: a study of 422 cases observed in the out-patient department of the roosevelt hospital of the city of New York. Ann Surg. 1929;89(4):600-6.

5. Andersen K, Jensen PO, Lauritzen J. Treatment of clavicular fractures. Figure-ofeight bandage versus a simple sling. Acta Orthop Scand. 1987;58(1):71-4.

6. Hill JM, McGuire MH, Crosby LA. Closed treatment of displaced middle-third fractures of the clavicle gives poor results. J Bone Joint Surg Br. 1997;79(4):537-9.

7. Robinson CM, Court-Brown CM, McQueen MM, Wakefield AE. Estimating the risk of nonunion following nonoperative treatment of a clavicular fracture. J Bone Joint Surg Am. 2004;86(7):1359-65

8. Stegeman SA, De Jong M, Sier CF, Krijnen P, Duijff JW, Van Thiel TP, et al. Displaced midshaft fractures of the clavicle: non-operative treatment versus plate fixation (Sleutel-TRIAL). A multicentre randomised controlled trial. BMC Musculoskelet Disord. 2011;12:196.

9. Van der Meijden OA, Gaskill TR, Millett PJ. Treatment of clavicle fractures: current concepts review. J Shoulder Elbow Surg. 2012;21(3):423-9.

10. Partal G, Meyers KN, Sama N, Pagenkopf E, Lewis PB, Goldman A, et al. Superior versus anteroinferior plating of the clavicle revisited: a mechanical study. J Orthop Trauma. 2010;24(7):420-5.

11. Allman FL Jr. Fractures and ligamentous injuries of the clavicle and its articulation. J Bone Joint Surg Am. 1967;49(4):774-84.

12. VanBeek C, Boselli KJ, Cadet ER, Ahmad CS, Levine WN. Precontoured plating of clavicle fractures: decreased hardware-related complications? Clin Orthop Relat Res. 2011;469(12):3337-43.

13. Fanter NJ, Kenny RM, Baker CL, Baker CL. Surgical treatment of clavicular fractures in the adolescent athlete. Sports Health. 2015;7(2):13741. 
14. Constant CR, Murley AH. A clinical method of functional assessment of the shoulder. Clin Orthop Relat Res. 1987;214:160-4.

15. Andersen K, Jensen PO, Lauritzen J. Treatment of clavicular fractures. Figure-of-eight bandage versus a simple sling. Acta Orthop Scand. 1987;58(1):71-4

16. NEER CS 2nd. Nonunion of the clavicle. J Am Med Assoc. 1960;172:1006-11.

17. Rowe CR. An atlas of anatomy and treatment of midclavicular fractures. Clin Orthop Relat Res. 1968;58:29-42.

18. Brinker MR, Edwards TB, O'Connor DP. Estimating the risk of nonunion following nonoperative treatment of a clavicular fracture. J Bone Joint Surg Am. 2005;87(3):676-7.

19. McKee MD, Pedersen EM, Jones C, Stephen DJ, Kreder HJ, Schemitsch EH, et al. Deficits following nonoperative treatment of displaced midshaft clavicular fractures. J Bone Joint Surg Am. 2006;88(1):35-40.

20. Böstman O, Manninen $\mathrm{M}$, Pihlajamäki H.Complications of plate fixation in fresh displaced midclavicular fractures. J Trauma. 1997;43(5):778-83.
21. Cho CH1, Song KS, Min BW, Bae KC, Lee KJ. Operative treatment of clavicle midshaft fractures: comparison between reconstruction plate and reconstruction locking compression plate. Clin Orthop Surg. 2010;2(3):154-9.

22. Dhoju D, Shrestha D, Parajuli NP, Shrestha R, Sharma V. Operative fixation of displaced middle third clavicle (Edinburg Type 2) fracture with superior reconstruction plate osteosynthesis. Kathmandu Univ Med J. 2011;9(36):286-90.

23. Wang XH, Guo WJ, Li AB, Cheng GJ, Lei T, Zhao YM. Operative versus nonoperative treatment for displaced midshaft clavicle fractures: a meta-analysis based on current evidence. Clinics (Sao Paulo). 2015;70(8):584-92.

Cite this article as: Panthi S, Shrestha R, Shakya R. Radiological and functional outcome of displaced mid-shaft clavicular fracture managed with open reduction and internal fixation with precountered anatomical clavicular locking plate: a prospective study. Int J Res Orthop 2020;6:878-83. 